\title{
Combined Influence of Fluoride and Biofilms on the Biotribocorrosion Behavior of Titanium Used for Dental Applications
}

\author{
Helena V. Cruz ${ }^{1,2,3} \cdot$ Mariana Henriques $^{2} \cdot$ Wim Teughels $^{4} \cdot$ Jean-Pierre Celis $^{5}$. \\ Luís A. Rocha ${ }^{1,3,6}$
}

Received: 21 March 2015/Revised: 30 May 2015/ Accepted: 17 June 2015/Published online: 1 July 2015

(C) Springer International Publishing AG 2015

\begin{abstract}
Dental implant failures occur mainly due to biofilm infections and mastication micro-movements or load stresses that may induce wear degradation. Dental implants' microgaps are highly susceptible areas for biofilm formation and fluoride retention. Although fluoride is an antimicrobial agent widely used in caries prevention, its influence on biofilms under sliding wear remains unknown. The main aim of this work was to assess the effect of mixed biofilms and fluoride on the tribocorrosion behavior of titanium. Streptococcus mutans and Candida albicans mixed biofilms were cultured for 8 days on ground and polished commercially pure titanium. Biofilms' formation was influenced by topography: higher roughness surfaces presented higher levels of biomass. Reciprocating sliding tests were performed on both surfaces, with and without biofilms, immersed in artificial saliva in the absence or presence of fluoride ( 30 and $227 \mathrm{ppm} \mathrm{F}^{-}$). The low friction
\end{abstract}

Helena V. Cruz

helenavcruz@ceb.uminho.pt

1 MEMS-UMINHO - Center MicroElectroMechanical Systems, Universidade do Minho, Guimarães, Portugal

2 CEB - Centre of Biological Engineering, LIBRO Laboratório de Investigação em Biofilmes Rosário Oliveira, Universidade do Minho, Braga, Portugal

3 IBTN/Br - Brazilian Branch of the Institute of Biomaterials, Tribocorrosion and Nanomedicine, Bauru, Brazil

4 Department of Oral Health Sciences, KU Leuven, Leuven, Belgium

5 MTM - Department of Materials Engineering, KU Leuven, Leuven, Belgium

6 Department of Physics, Faculdade de Ciências, UNESP Universidade Estadual Paulista, Campus de Bauru, Bauru, Brazil coefficient registered indicated the lubricating effect of biofilms on titanium surfaces. Fluoride was also found to have lubricating properties on titanium during sliding, probably due to the precipitation of calcium fluoride (or like) salts. The presence of fluoride influenced the biotribological behavior of titanium surfaces covered with biofilms, facilitating their structural disruption and detachment. Nevertheless, open circuit potential tests reduced the corrosion of titanium in the presence of fluoride $\left(227 \mathrm{ppm} \mathrm{F}^{-}\right.$) and biofilms. In conclusion, it is highlighted that fluoride interaction with biofilms can significantly influence the tribological properties of commercially pure titanium in the oral cavity.

Keywords Dental implants - Tribology - Biotribology · Fluoride $\cdot$ Biofilms $\cdot$ Friction $\cdot$ Wear

\section{Introduction}

Dental implants have become increasingly accepted worldwide, exceeding over 2 million placements annually. Implant therapies are also reported to be highly successful with implant survival rates of $91.5 \%$ after 16-22 years [1]. Nevertheless, despite great improvements, dental implants may still fail mainly due to microbial infections and occlusal load stresses [2-5]. In fact, the loss of dental implants after long-term implantation is caused by bacterial infections in up to $30 \%$ of the cases [4].

Titanium (Ti) and its alloys are widely used in dentistry essentially due to their biocompatibility and excellent corrosion resistance provided by the ability of Ti to spontaneously form a highly stable passive oxide layer over the surface when in contact with air [6]. The low density, low thermal conductivity, and good mechanical properties of $\mathrm{Ti}$ 
make it ideal for oral applications [5, 6]. In fact, cp-Ti (grade 2-4) is the most common material used to create the root of dental implants since Brånemark proposed the first implant systems in the 60s [6, 7]. Also, recent scientific reports in the literature review the surface characteristics of implants present in the market [8].

Biotribology comprises the study of friction, lubrication, and wear of surfaces subjected to a relative contact movement in a biological environment [5]. Dental implants are good examples of biotribological systems as they undergo cyclic micro-movements at implant-bone and implantabutment interfaces during mastication, generating wear debris and corrosion products and concomitantly leading to material loss [5, 9-12]. Due to the abrasion against bone or other implant materials, Ti passive films may degrade in sliding contacts and cause implant wear [11], or even disrupt at very low shear stresses [13]. Continuous sliding motions possibly lead to serious damages on Ti surfaces, including material loss, material displacement due to plastic deformation, fissures that might grow and propagate through the material, and changes in surface chemistry like oxidation [14]. The influence of oral fluids and microorganisms on the tribological behavior of implant surfaces is also of great concern. Recently, Souza et al. [15] brought new knowledge to the field by investigating the influence of oral biofilms on the wear behavior of Ti. Nevertheless, relative little attention has been given to the biotribological study of dental implants on the oral environment $[9,16]$.

Microbial adhesion is the first and most important step in dental implant infection followed by biofilm formation [17]. The oral cavity provides an excellent environment for biofilms, especially at gaps and confined areas. Microgaps on dental implants interfaces may cause microbial leakage [18] and lead to peri-implant infections since microorganisms can penetrate through $10 \mu \mathrm{m}$ gaps [19]. Among the microorganisms present in the oral cavity, lactic acid-producing bacterium Streptococcus mutans is of utmost importance as it is a well-known potential inducer of dental caries and has been shown to have an important role in periimplant diseases [20]. This pathogenic species is frequently associated with Candida albicans, a commensal fungal species often found in peri-implant lesions [21]. However, very little information is available on the formation of fungal or mixed biofilms on dental implants' surfaces.

Fluoride is highly used to prevent microbial infection and caries formation. It can be found in toothpastes (up to $1500 \mathrm{ppm} \mathrm{F}^{-}$), topical applications (9000-12300 $\mathrm{ppm} \mathrm{F}^{-}$), mouthrinses (227-500 $\mathrm{ppm}^{-}$), and glass ionomer cements (less than $50 \mathrm{ppm} \mathrm{F}^{-}$) [22, 23]. After application, fluoride can be retained in several micro-areas in the oral cavity and undergo a constant dilution by saliva flow. However, fluoride ions are known to be corrosive to Ti [23, 24]. Although the tribocorrosion behaviors of $\mathrm{Ti}$ and $\mathrm{Ti}-$
6Al-4V were recently evaluated in artificial saliva (AS) containing varying fluoride concentrations [22, 25], a deeper investigation on the influence of fluoride on the tribological behavior of $\mathrm{Ti}$ is needed.

Surface roughness is known to play a major role in microbial adhesion processes [26], yet implants' optimal surface topography has been highly contested regarding microorganisms' adhesion and proliferation. Some authors reported that surfaces with increased roughness enhance bacterial adhesion, whereas highly polished surfaces limit the initial biofilm formation in vivo and in vitro [17, 2730]. However, others did not find significant differences in biofilm formation between smooth and rough Ti surfaces $[31,32]$. These considerations probe to further investigations to determine how surface characteristics affect biofilms' adhesion.

The objective of this work is to evaluate the simultaneous influence of fluoridated AS solutions on the tribological behavior of cp-Ti with two different surface finishes in the presence of biofilms.

\section{Materials and Methods}

\subsection{Materials}

Substrate samples of $10 \times 10 \times 1 \mathrm{~mm}^{3}$ were cut from a commercially pure (cp)-Ti grade 2 sheet (Goodfellow Cambridge Ltd., Cambridge, UK). The two different surface topographies tested (ground and polished cp-Ti) were mechanically wet ground at 2.5 bar with an automatic polishing machine (Model TF250 Pressair, Jean Wirtz, Dusseldorf, Germany) using increasing fineness silicon carbide (SiC) emery papers. Ground surfaces were created using $\mathrm{SiC}$ papers ranging from 600 to 1200 mesh, reaching an average roughness $\left(R_{\mathrm{a}}\right)$ of about $0.4 \mu \mathrm{m}$. For polished surfaces, $\mathrm{SiC}$ papers were used down to 2400 mesh, and samples were additionally polished with an OP-Chem polishing cloth, wetted with an OP-S colloidal silica $\left(\mathrm{SiO}_{2}\right)$ suspension with a mean grain size of $0.25 \mu \mathrm{m}$ with the addition of $15 \%$ hydrogen peroxide $\left(\mathrm{H}_{2} \mathrm{O}_{2}\right)$ as reported in [33]. Mirror-like surfaces were obtained with $\mathrm{R}_{\mathrm{a}} \approx 0.04 \mu \mathrm{m}$. All samples were ultrasonically cleaned in acetone for $15 \mathrm{~min}$, isopropanol for $10 \mathrm{~min}$, and deionized water for $5 \mathrm{~min}$, sequentially. Finally, they were dried by hot blowing air and kept in a desiccator until use. Samples were also sterilized in a steam autoclave at $121^{\circ} \mathrm{C}$ for $20 \mathrm{~min}$.

\subsection{Media and Solutions}

Fusayama's [34] AS was used as the immersion electrolyte solution used in all assays (Table 1). To evaluate the effect of fluoride on the wear of cp-Ti, different amounts of 
sodium fluoride $(\mathrm{NaF})$ were added to AS solutions. Concentrations of 0.066 and $0.5 \mathrm{~g} \mathrm{~L}^{-1} \mathrm{NaF}$ were prepared in AS to reach a final concentration of 30 and $227 \mathrm{ppm} \mathrm{F}^{-}$, respectively (pH 5.3-5.7).

For biofilm formation, an enriched tryptic soy broth (TSB) medium (TSBMPU20\%S) was prepared containing $30 \mathrm{~g} \mathrm{~L}^{-1} \mathrm{TSB} ; 2.5 \mathrm{~g} \mathrm{~L}^{-1}$ hog gastric mucin; $5 \mathrm{~g} \mathrm{~L}^{-1}$ peptone; $1 \mathrm{~g} \mathrm{~L}^{-1}$ urea; $2 \mathrm{~g} \mathrm{~L}^{-1}$ yeast extract; and $200 \mathrm{~g} \mathrm{~L}^{-1}$ sucrose $[15,35]$. Mucin, a salivary pellicle protein, was used in this study to promote $S$. mutans and $C$. albicans adhesion to the substrate [21].

\subsection{Biofilms}

S. mutans ATCC 25175 (American Type Culture Collection) and C. albicans cells obtained from the oral cavity of a 42-year-old patient (identified by molecular methods and belonging to the UMinho Biofilm group collection) were used to form mixed biofilms.

Bacteria and yeast strains were subcultured on tryptic soy agar (TSA) and Sabouraud dextrose agar (SDA), respectively, for $48 \mathrm{~h}$ at $37{ }^{\circ} \mathrm{C}$. Bacteria and yeast were then inoculated in TSB supplemented with $2 \%$ sucrose (TSB2\%S) and Sabouraud dextrose broth (SDB), respectively, and incubated for $18 \mathrm{~h}$ at $37^{\circ} \mathrm{C}$ and $150 \mathrm{rpm}$. Cells were then harvested by centrifugation at $4500 \mathrm{rpm}$ and room temperature for $10 \mathrm{~min}$. The resultant pellets were washed twice with $0.9 \% \mathrm{NaCl}$ and centrifuged again. The obtained pellets were separately resuspended in TSBMPU20\%S medium. S. mutans suspensions were vortexed for $5 \mathrm{~min}$ to disrupt and destroy aggregates and detach adherent cells, thus breaking the Streptococcus chains. The optical density of each organism was adjusted to 0.5 at $600 \mathrm{~nm}\left(\mathrm{OD}_{600}\right)$ in TSBMPU20\%S medium.

Previously sterilized cp-Ti samples were placed into wells from a standard 24-well culture plate, and $1 \mathrm{~mL}$ of TSBMPU20\% $\mathrm{S}$ with each cell suspension was added to each well. The well plates were then incubated at $5 \% \mathrm{CO}_{2}$, $37{ }^{\circ} \mathrm{C}$ and $120 \mathrm{rpm}$ for 8 days. Culture medium was changed every 2 days.

Biofilm biomass was quantified after 8 days by crystal violet $(\mathrm{CV})$ staining. $\mathrm{Cp}$-Ti samples with biofilms were

Table 1 Composition of the Fusayama's artificial saliva (AS) [44]

\begin{tabular}{|c|c|}
\hline Chemical compounds & Composition $\left(\mathrm{g} \mathrm{L}^{-1}\right)$ \\
\hline $\mathrm{NaCl}$ & 0.4 \\
\hline $\mathrm{KCl}$ & 0.4 \\
\hline $\mathrm{CaCl}_{2} \cdot 9 \mathrm{H}_{2} \mathrm{O}$ & 0.795 \\
\hline $\mathrm{Na}_{2} \mathrm{~S} .9 \mathrm{H}_{2} \mathrm{O}$ & 0.005 \\
\hline $\mathrm{NaH}_{2} \mathrm{PO}_{4} \cdot 2 \mathrm{H}_{2} \mathrm{O}$ & 0.69 \\
\hline Urea & 1 \\
\hline
\end{tabular}

placed into new wells and gently washed twice with $0.9 \%$ $\mathrm{NaCl}$ to remove non-attached cells. Methanol $(2 \mathrm{~mL}$, $15 \mathrm{~min}$ ) was added to each well to fix biofilms. After methanol removal, specimens were left to dry at room temperature. $\mathrm{CV}$ staining ( $1 \mathrm{~mL}, 1 \%$ in water) was added to each well and allowed to stain for $5 \mathrm{~min}$. After CV removal, specimens were washed twice with deionized water and dried at room temperature. Acetic acid $(2 \mathrm{~mL}, 33 \%$ in water) was added to dissolve and remove $\mathrm{CV}$ from biofilms. Finally, the average absorbance of the resultant acetic acid solutions was read at $570 \mathrm{~nm}$ and expressed as OD per $\mathrm{mL}$.

\subsection{Biotribological Tests}

Wear tests were carried out in a ball-on-plate reciprocating sliding configuration, using a Modular Universal Surface Tester tribometer (MUST, Falex Tribology N. V., Rotselaar, Belgium). TETRA-view software was used to evaluate the coefficient of friction (COF) from tangential force versus displacement amplitude plots. The sliding tests were performed against a 5-mm-diameter alumina $\left(\mathrm{Al}_{2} \mathrm{O}_{3}\right)$ halfball (Ceratec, Geldermalsen, Netherlands) pin at a normal load of $100 \mathrm{mN}$ for 1000 cycles, at a sliding frequency of $1 \mathrm{~Hz}$ and a linear displacement of $500 \mu \mathrm{m}$. The maximum contact pressure calculated was $288 \mathrm{MPa}$ with a theoretical average contact pressure of about $190 \mathrm{MPa}$.

\subsection{Biotribocorrosion Tests}

Tribocorrosion tests were performed on a pin-on-plate tribometer (UMT-2, CETR, Campbell, USA) with the same reciprocating sliding parameters as stated above for biotribological tests. The COF recorded is not shown here due to identical results. The electrochemical tests were carried out with a potentiostat (Reference 600, Gamry Instruments, Philadelphia, USA) coupled to the Framework software (Gamry Instruments, Philadelphia, USA). A three-electrode cell was used for all electrochemical measurements containing a saturated calomel electrode (SCE) as reference electrode; a platinum (Pt) electrode as counter electrode; and cp-Ti test specimen as working electrode, in contact with the electrical wiring via a copper plate placed under the sample holder. The open circuit potential was monitored during the initial stabilization before the start of the sliding tests, during reciprocating sliding, and during the final stabilization once the sliding tests were ended. The biotribocorrosion assay was only performed on polished cp-Ti samples.

\subsection{Surface Characterization}

Cp-Ti surfaces were analyzed after tribological tests by scanning electron microscopy (SEM) (Nova 600 NanoLab, FEI Company, Hillsboro, USA) at $10 \mathrm{kV}$. Samples were 
Fig. 1 Coefficient of friction (COF) of ground and polished cp-Ti samples covered or not with biofilms, immersed in artificial saliva (AS) $(100 \mathrm{mN}$ applied load, $500 \mu \mathrm{m}$ displacement amplitude, $1 \mathrm{~Hz}$, up to 1000 cycles)

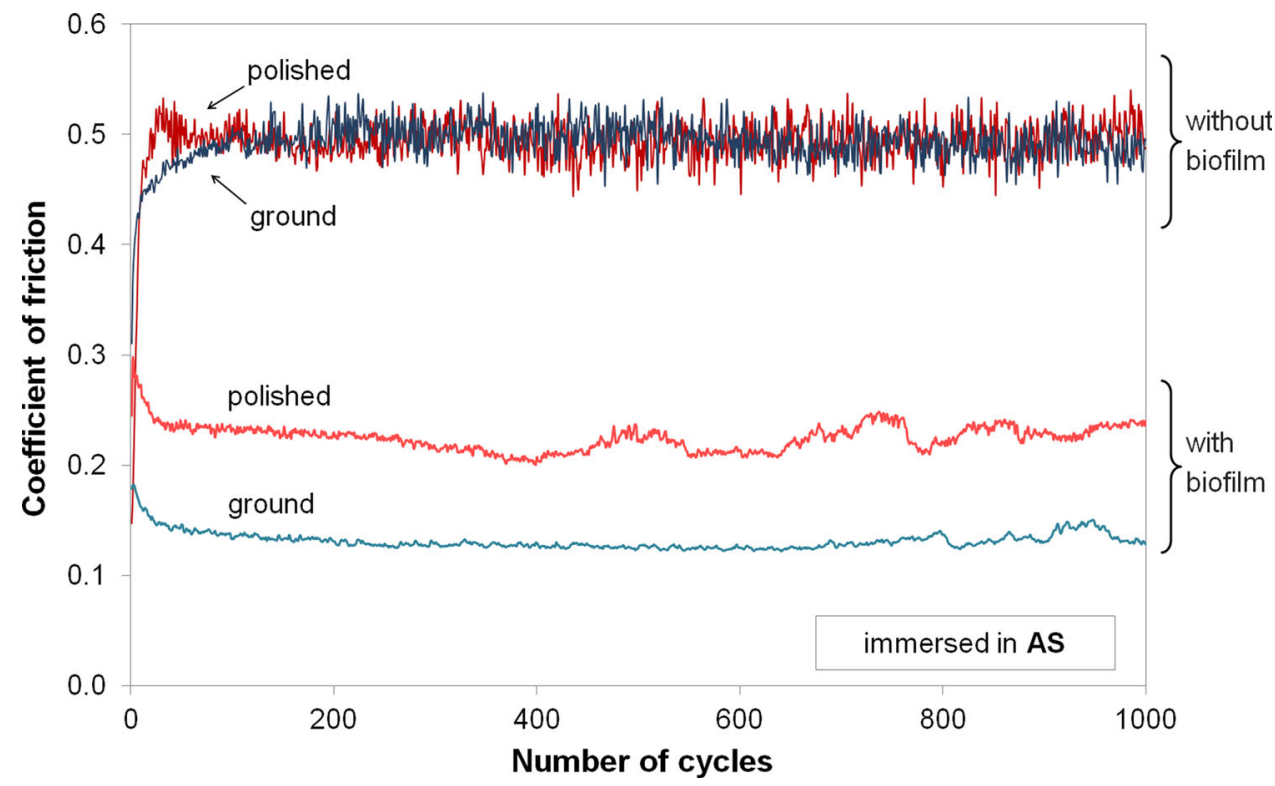

washed twice with distilled water and dehydrated through a series of washes using increasing concentrations of ethanol. Samples were then sputter-coated with $5 \mathrm{~nm}$ gold thin film and mounted on aluminum stubs with carbon tape. Energydispersive X-ray spectroscopy (EDS) (Pegasus X4M, EDAX, New Jersey, USA) integrated in a SEM (Nova 200 NanoLab, FEI Company, Hillsboro, USA) was used to characterize the elemental composition of the precipitated salts.

\subsection{Statistical Analysis}

All experiments were triplicated with the exception of the tribocorrosion assays which were duplicated. The results were statistically analyzed using t-student test, with $p$ value $<0.05$ considered as statistically significant.

\section{Results and Discussion}

\subsection{Biofilm Quantification}

Biofilm biomass obtained by $\mathrm{CV}$ staining was significantly different on both cp-Ti surfaces. The amount of biofilm biomass found on ground samples was higher (average Abs $=4.82 \pm 0.56$ ) than on polished ones (average Abs $=2.13 \pm 0.58$ ). The higher amount of biofilm biomass on ground samples might be related to the existence of a superior colonization area provided by the higher roughness morphology. In fact, Barbour et al. [30] recently reported that $S$. mutans might be better retained on surfaces with pits and crevices, and Pereira-Cenci et al. [36] showed that $S$. mutans increases the growth of $C$. albicans when co- aggregated. Thus, the results obtained in this study imply that biofilms development is influenced by the surface topography, in agreement with previous studies [17, 27-30] which state that microbial adhesion and the succeeding biofilm formation are enhanced by an increased roughness.

It should be noticed that the biomass of biofilms grown on polished cp-Ti used in the biotribocorrosion assay was lower (average $\mathrm{Abs}=1.02 \pm 0.25$ ) than other assays in this study, mostly due to different $\mathrm{CO}_{2}$ growth conditions in a different microbiology laboratory.

\subsection{Biofilms and Topography Influence on Titanium Tribology}

To assess the influence of biofilms and topography on the tribological behavior of $\mathrm{cp}$-Ti, sliding tests were performed on ground and polished surfaces covered or not with biofilms, and immersed in AS (Fig. 1). The COF measured on cp-Ti without biofilms was identical for both surface finishes. The fast COF initial increase is related to the surface adaptation and subsequent destruction of the passive surface film $\left(\mathrm{TiO}_{2}\right)$ covering $\mathrm{Ti}$. The achievement of these processes took a slightly longer time on ground surfaces (Fig. 1) because of the existence of larger topographic peaks. The initial COF evolution and the subsequent constant COF value (0.5) verified through the rest of the sliding tests confirmed that the alumina ball reached and slit onto fresh Ti surface (Fig. 2a), in agreement with previous studies [10, 15].

The presence of biofilms reduced significantly the COF which remained constant for both surface finishes throughout the whole sliding tests duration (Fig. 1), confirming the lubricating properties of biofilms already 

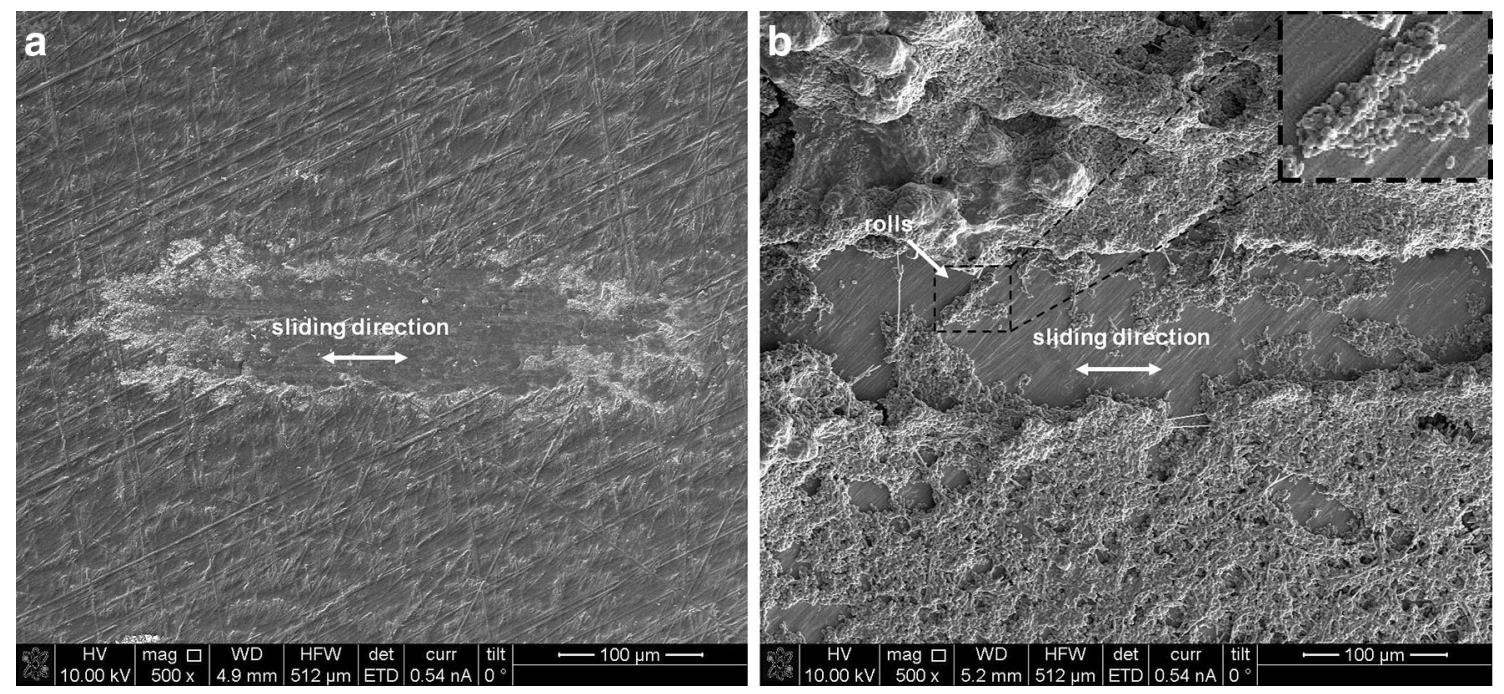

Fig. 2 Scanning Electron Microscopy (SEM) micrographs of the complete wear tracks of a a ground cp-Ti surface without biofilm and $\mathbf{b}$ a ground $\mathrm{cp}-\mathrm{Ti}$ surface covered with biofilms evidencing the presence of rolls

described $[15,35]$. These results indicate that $S$. mutans and $C$. albicans mixed biofilms are not destroyed or removed from the surface in the sliding track, but remain intact, preventing any direct contact between the alumina ball and Ti. In addition, the lower COF recorded on ground samples covered with biofilms (Fig. 1) might be related to the higher biofilm biomass present on those samples. In fact, this highlights the protective effect of biofilms on $\mathrm{Ti}$ oxide film under sliding.

At the end of the sliding tests, some microorganisms still adhered onto the Ti surface, while detachment took place in other parts of the sliding track (Fig. 2b). Recently, Souza et al. [15] reported that biofilms can undergo plastic deformation under sliding at $100 \mathrm{mN}$. That phenomenon, pursued by the rupture and agglomeration of the exopolymeric matrix, led to the formation of "rolls". These ruptured films of microorganisms and matrix were found to roll under the ball along the sliding track and perpendicularly to the sliding direction, thus protecting the underneath Ti substratum. The same phenomenon was observed in this study, as visible in Fig. 2b (see arrow). Therefore, it may be stated that the passive film on $\mathrm{Ti}$ was kept intact during sliding due to the presence of biofilms. In addition, the alumina balls used as counterbodies on samples with biofilms did not show, to naked eye, any sign of wear or mass transfer. On the contrary, balls slit against uncovered surfaces presented a black dot at the end of the sliding test, evidence of a mass transfer to the counterbody and a wear out of cp-Ti.

\subsection{Fluoride Influence on Titanium Tribocorrosion}

Reciprocating sliding tests were performed on both cp-Ti surfaces covered or not with biofilms, immersed in AS in the absence or presence of fluoride (30 or $227 \mathrm{ppm} \mathrm{F}^{-}$Figs. 3, 4, respectively) reproducing simulating fluoride concentrations that can be found in the oral cavity. Watson et al. [37] reported a fluoride concentration around $30 \mathrm{ppm}$ $\mathrm{F}^{-}$in oral biofilms after being exposed to $1000 \mathrm{ppm} \mathrm{F}^{-}$for $30 \mathrm{~s}$ and washed in saliva for $12 \mathrm{~h}$ (approximate time period between brushing episodes). In addition, $227 \mathrm{ppm}$ $\mathrm{F}^{-}$was detected in saliva and oral biofilms after tooth brushing with fluoridated toothpaste [37].

The quick initial increase of COF observed on all uncovered samples in the presence of fluoride (Figs. 3, 4) evidenced the destruction of the passive film, as verified in the AS solution (Fig. 1). A slight decrease of COF was also verified on all uncovered samples (Figs. 3, 4 vs. 1). This behavior must be related to the addition of fluoride to the AS and explained by the good lubricating properties of this element. Indeed, fluorinated organic compounds are used as anti-wear additives in lubricating oils [38]. These compounds are supposed to protect metal surfaces from wear by the formation of metal fluorides through tribochemical reactions. Moreover, fluoride has also been shown to reduce in vitro and in situ tooth wear [39-44]. The anti-wear action of fluoride seems to improve at increasing concentrations of sodium fluoride $(\mathrm{NaF})$ and lower pHs [41, 44, 45]. This protective behavior might rely on the formation of a stable and less soluble salt, such as calcium fluoride (or like) deposits, or even fluorohydroxyapatite $[40,41,46]$. Actually, prevention of enamel abrasion by fluoride was recently demonstrated by Lagerweij et al. [41] attributing it to the deposition of $\mathrm{CaF}_{2}$-like layers on top of the enamel surface. In modern tribology, calcium fluoride is a well-known and widely used fluoridebased solid lubricant. The addition of such solid lubricant 
Fig. 3 Coefficient of friction (COF) of ground and polished cp-Ti samples covered or not with biofilms, immersed in AS with $30 \mathrm{ppm} \mathrm{F}^{-}$(30F) $(100 \mathrm{mN}$ applied load, $500 \mu \mathrm{m}$ displacement amplitude, $1 \mathrm{~Hz}$, up to 1000 cycles)
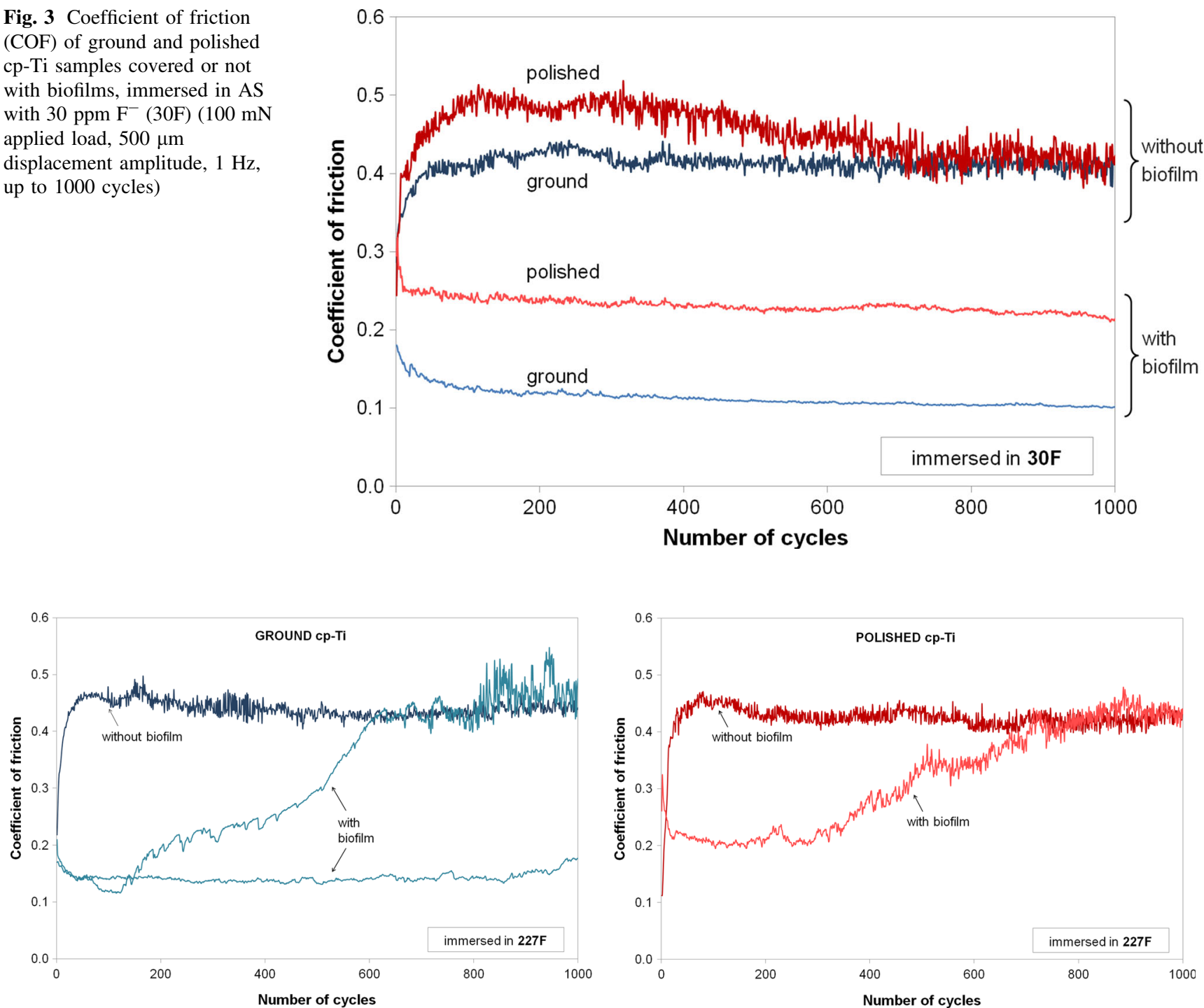

Fig. 4 Coefficient of friction (COF) of a ground and $\mathbf{b}$ polished cp-Ti samples covered or not with biofilms, immersed in AS with 227 ppm $\mathrm{F}^{-}$ (227F) (100 mN applied load, $500 \mu \mathrm{m}$ displacement amplitude, $1 \mathrm{~Hz}$, up to 1000 cycles)

to a tribological contact reduces friction and wear effectively by preventing adhesion, enabling tribo-chemical reactions, and offering a low shear strength [47]. Consequently, calcium fluoride has been used to improve the tribological properties of self-lubricating composites widely used in automotive industries, aviation, and electronic devices [47], or even to improve the performance of machining processes [48].

In this study, the immersion of cp-Ti samples in AS containing $\mathrm{NaF}$ involved the precipitation of calcium fluoride (or like) salts (Fig. 5), probably due to the existence of calcium ions in the AS solution and fluoride ions in $\mathrm{NaF}$. Figure 5a reveals, at high magnification, the calcium fluoride (or like) salts formed on the surface of an uncovered polished sample immersed in $227 \mathrm{ppm} \mathrm{F}^{-}$and not subjected to wear, while Fig. $5 \mathrm{~b}$ shows the EDS spectrum of the precipitated salts. In vitro studies indicate that fluoride concentrations of $300 \mathrm{ppm}$ (at pH 7) or $100 \mathrm{ppm}$ (at pH 5) are critical to induce a spontaneous precipitation of calcium fluoride [49]. The $227 \mathrm{ppm} \mathrm{F}^{-}$solution used in this study, with a pH between 5.3 and 5.7, might have caused an almost spontaneous precipitation of calcium fluoride. However, in this study, the precipitation process also occurred for immersions in $30 \mathrm{ppm} \mathrm{F}^{-}$, although slower and more gradual possibly due to lower fluoride concentration. The presence of these salts on cp-Ti surfaces subjected to wear probably promotes the lowering of the COF, as verified on uncovered samples in the presence of fluoride (Figs. 3, 4). This effect is more perceptible on uncovered polished cp-Ti immersed in $30 \mathrm{ppm} \mathrm{F}^{-}$(Fig. 3), as confirmed by the slow stabilization of the COF along the sliding tests. The continuous salt precipitation taking place 


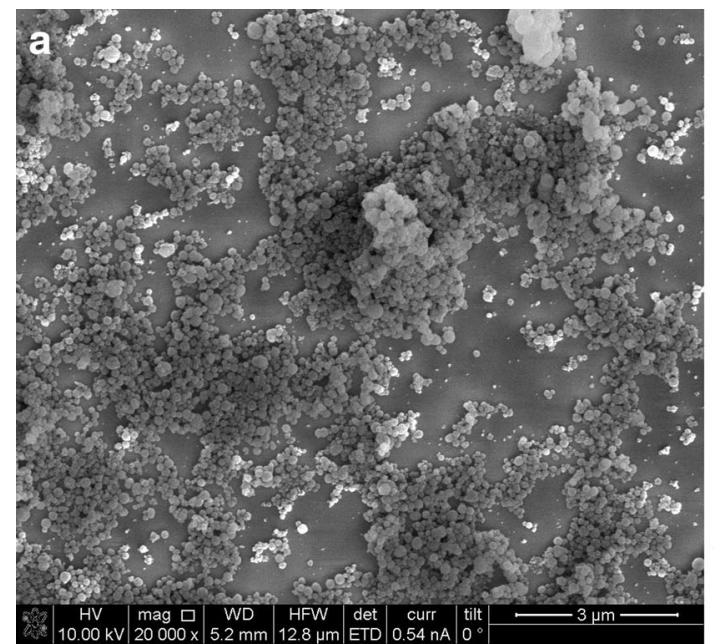

Fig. 5 a Scanning electron microscopy (SEM) micrograph showing calcium fluoride salts precipitated on a polished cp-Ti surface without biofilms, in an area not subjected to sliding, after immersion in

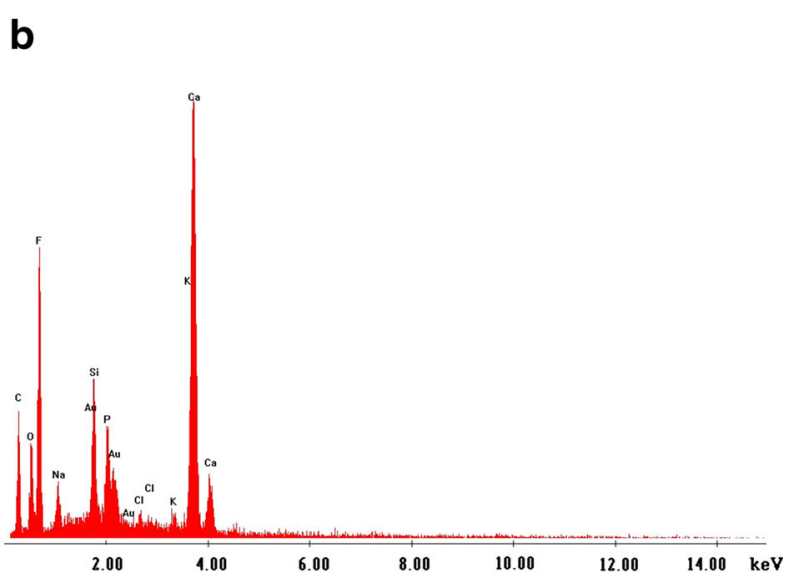

$227 \mathrm{ppm} \mathrm{F}^{-}$; $\quad$ b Energy-dispersive X-ray spectroscopy (EDS) spectrum showing the elemental composition of the precipitated salts

higher than the ones recorded in AS. Thermodynamically, OCP discloses the chemical reactivity of titanium with the environment in an ion conductive electrolyte. Higher and increasing values of OCP during sliding indicate a lower tendency to corrosion of materials under such conditions. Therefore, these results imply that cp-Ti immersed in $227 \mathrm{ppm} \mathrm{F}^{-}$presents lower susceptibility to corrosion than in AS. Thus, this behavior can be attributed to the existence of calcium fluoride (or like) salts on cp-Ti surface which protect and provide a higher corrosion resistance. On the other hand, the OCP variation in AS may be attributed to an initial destruction and removal of the passive film (depassivation), and then to a cyclic repassivation and removal of the film, allowing the exposure of active $\mathrm{Ti}$ to the electrolyte (Fig. 6). Moreover, the outcomes obtained in this study regarding the tribocorrosion behavior of $\mathrm{cp}-\mathrm{Ti}$ immersed in $227 \mathrm{ppm} \mathrm{F}^{-}$might help to explain some results reported earlier by Souza et al. [22]. The authors studied the tribocorrosion behavior of cp-Ti in AS containing varying fluoride concentrations (from 0 to $12300 \mathrm{ppm}$ ) by monitoring OCP throughout the sliding tests, allowing the evaluation of their electrochemical behavior. Interestingly, the higher OCP values were recorded precisely on samples immersed in $227 \mathrm{ppm} \mathrm{F}^{-}$ during sliding, just like in this study. Still during sliding, a slightly increasing OCP was noticed in the $227 \mathrm{ppm} \mathrm{F}^{-}$ solution that was not observed in any other condition except for the $30 \mathrm{ppm} \mathrm{F}^{-}$, but at a lower rate [22]. Those observations were attributed to the chemical reactivity of $\mathrm{Ti}$ with the solutions fluoride concentration [22]. However, the continuous precipitation of calcium fluoride (or like) salts reported here above may be the reason why $\mathrm{cp}-\mathrm{Ti}$ surfaces present lower tendency to corrosion during 
Fig. 6 Open circuit potential (OCP) evolution of polished cpTi samples immersed in AS and AS with 227 ppm F$^{-}$(227F) before, during, and after reciprocating sliding tests

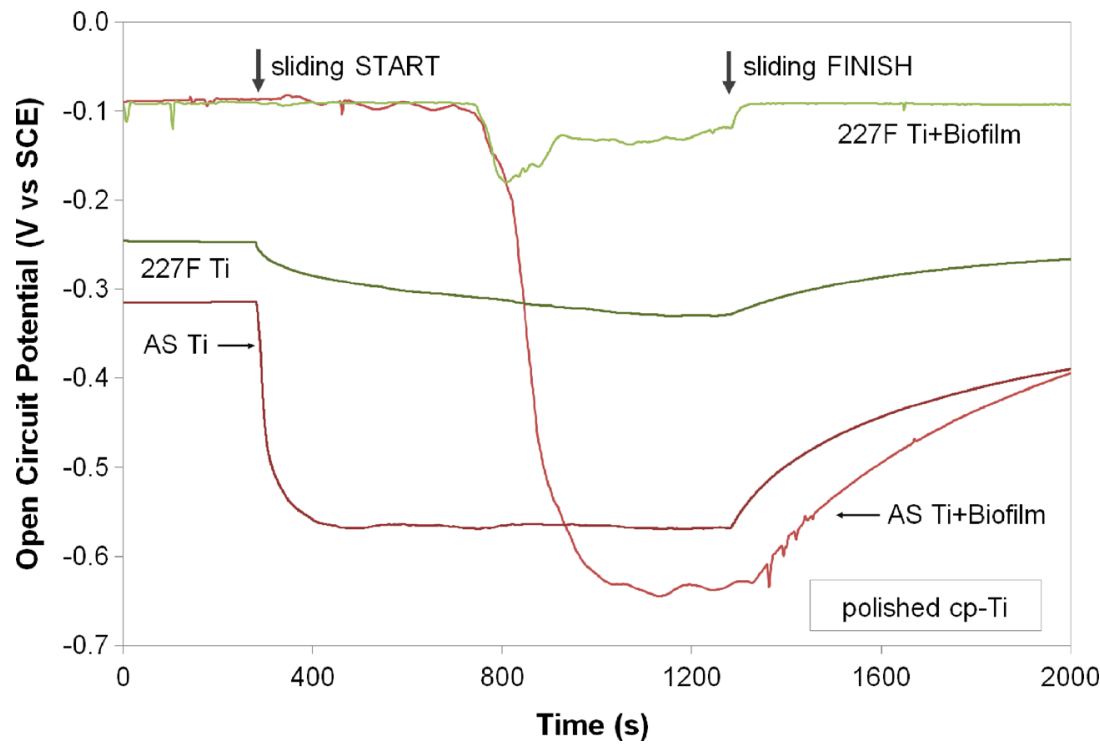

reciprocating sliding since they are covered by the salts. These salts are acting as lubricants on Ti protecting beneath surfaces against corrosion and wear.

\subsection{Simultaneous Influence of Fluoride and Biofilms on Titanium Biotribocorrosion}

In the presence of biofilms, the tribological behavior of samples immersed in 30 ppm F$^{-}$(Fig. 3) was very similar to the one of samples with the same roughness immersed in AS (Fig. 1), although slightly more stable. Likewise, ground samples presented lower COF than the polished ones. Moreover, no significant differences were found between the COF recorded on samples covered with biofilms and immersed in either AS or $30 \mathrm{ppm} \mathrm{F}^{-}$. Therefore, the lubricating effect of biofilms is also confirmed for cp-Ti samples immersed in $30 \mathrm{ppm} \mathrm{F}^{-}$. It is postulated that the "rolling" phenomenon mentioned here above also occurred in this case. However, in the presence of biofilms, the tribological behavior of both cp-Ti surfaces immersed in 227 ppm F $^{-}$(Fig. 4) was different from immersions in AS (Fig. 1) and $30 \mathrm{ppm} \mathrm{F}^{-}$(Fig. 3), implying that the effect of fluoride on biofilms is concentration dependent. Major differences were found between the tribological behavior of ground and polished surfaces immersed in $227 \mathrm{ppm} \mathrm{F}^{-}$ (Fig. 4a, b respectively). For instance, ground surfaces presented two distinct tribological behaviors (Fig. 4a). Some samples exhibited a low and constant COF value evidencing the lubricating properties of biofilms, whereas others exhibited an interesting dissimilar behavior, where after some sliding cycles, the COF increased gradually until reaching the characteristic $\mathrm{COF}$ value recorded on uncovered samples in the presence of fluoride (Fig. 4a). This last behavior was verified on all polished cp-Ti surfaces covered with biofilms and immersed in $227 \mathrm{ppm}$ $\mathrm{F}^{-}$(Fig. 4b), probably due to their lower biofilm biomass.

The OCP evolution of polished cp-Ti covered with biofilms immersed in AS and $227 \mathrm{ppm} \mathrm{F}^{-}$was recorded before, during, and after reciprocating sliding (Fig. 6). The pre-sliding stabilization of $\mathrm{cp}$-Ti in the presence of biofilms registered similar OCP values in AS and $227 \mathrm{ppm} \mathrm{F}^{-}$ $(\approx-0.1 \mathrm{~V}$ vs. SCE), higher than those observed for uncovered cp-Ti. OCP values remained constant for the first half of the tribocorrosion tests, suggesting that the alumina ball initially rubbed onto the biofilm with possible formation of rolls, causing no damage to the Ti subsurface, evidencing the lubricating properties of biofilms. Nevertheless, decays in OCP values were registered after a while. For cp-Ti with biofilms immersed in AS (AS Ti + Biofilm in Fig. 6), OCP decayed abruptly to values similar to those recorded during sliding on uncovered $\mathrm{cp}$ - $\mathrm{Ti}$ (AS $\mathrm{Ti}$ in Fig. 6). Values remained low on further sliding, probably due to the disruption of the biofilm and the subsequent oxide film destruction and Ti subsurface exposure to the electrolyte. This behavior, different from the one verified in the tribological assays here above where the COF remained constant throughout the test (Fig. 1) as biofilm remained unbroken, might be explained by different biofilm biomass on polished cp-Ti samples used for tribological and biotribocorrosion assays $\left(\mathrm{Abs}_{\text {tribological }}=2.13 \mathrm{vs}\right.$. Abs tribocorrosion $=1.02$ ). Lower biomass, in this last case, leads to a faster biofilm destruction and $\mathrm{Ti}$ exposure. On the other hand, the OCP of samples with biofilms immersed in 227 ppm F$^{-}$(227 F Ti + Biofilm in Fig. 6) only decreased to $\approx-0.18 \mathrm{~V}$ vs. SCE, which is still higher than the ones registered for uncovered cp-Ti (227F in Fig. 6). After some time, a slight increase of the OCP was recorded, which can be associated to a chemical reactivity decrease, enhancing a lower tendency to corrosion. This OCP increase is 


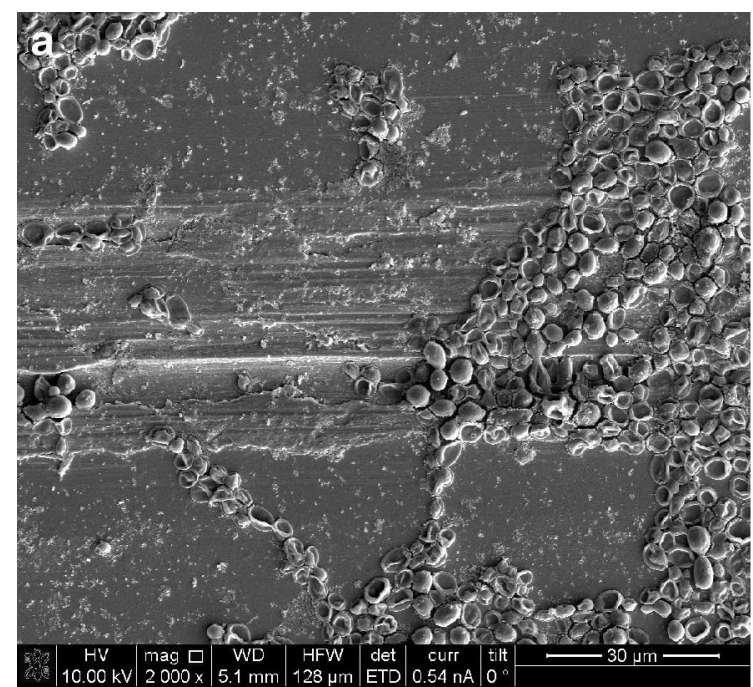

Fig. 7 Scanning electron microscopy (SEM) micrographs: a the middle of the wear track of a polished cp-Ti surface covered with biofilms after reciprocating sliding was performed in $227 \mathrm{ppm} \mathrm{F}^{-}$,

correlated with the COF evolution verified under the same conditions (Fig. 4b), emphasizing the continuous slat precipitation theory. After unloading at the end of sliding tests, stabilization occurred and the OCP values of cp-Ti immersed in both AS and $227 \mathrm{ppm} \mathrm{F}^{-}$increased (Fig. 6). Those recorded on cp-Ti with biofilms immersed in AS did not reach the values obtained before sliding, contrarily to immersion in $227 \mathrm{ppm} \mathrm{F}^{-}$. This behavior denotes that the final passive film possesses characteristics differently from the ones on films formed before mechanical damage. Therefore, as seen in Fig. 6, the presence of biofilms resulted in an increase of the electrochemical potential (i.e., decreased the tendency to corrosion). Also, interestingly, the OCP is not dependent on the presence of $\mathrm{F}^{-}$in the electrolyte, but appears to become totally dependent on the presence of the biomass.

The presented results indicate that a concentration of $227 \mathrm{ppm} \mathrm{F}^{-}$might be close to a transitional phase, indicating the point from which the fluoride concentration seems to affect biofilm structure and equilibrium, influencing the tribological behavior of cp-Ti samples covered with biofilms. After a number of sliding cycles, biofilm thickness starts to decrease as the alumina ball progressively disrupts and removes its matrix and cells. At the same time, the diffusion rate of fluoride ions through the extracellular matrix of biofilms might also influence their destruction and detachment since fluoride ions can reach micro-canals inside biofilms and the oral tissues underneath [37]. On further sliding, the ball gradually destroys and removes the oxide passive film till the Ti surface is reached and exposed. Consequently, wear particles from $\mathrm{Ti}$ and/or its oxide layer can be released to the sliding zone and neighboring areas, acting as an abrasive third body

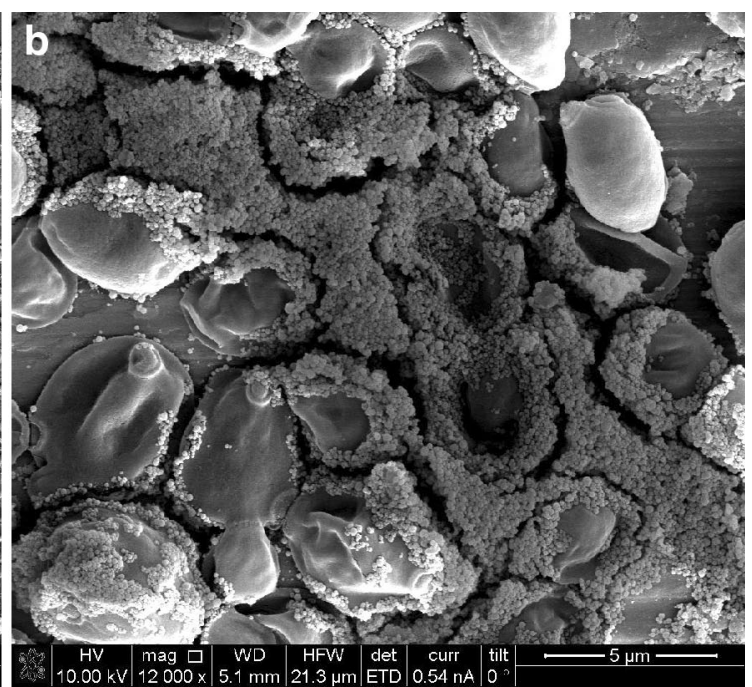

and $\mathbf{b}$ magnification of microbial cells from the same wear track covered by calcium fluoride (or like) salts

[10]. This is of major importance as, in vivo, dental implants can release wear debris to the adjacent tissues and oral cavity, ultimately leading to infections and being extremely prejudicial [50]. Damages are easily observed in the wear track of polished surfaces originally covered with biofilms and immersed in 227 ppm F $^{-}$(Fig. 7a), confirming the evolution of COF and OCP values, and the transitional phase behavior (Figs. 4b, 6). The causes for such transitional phase behavior are not fully understood. Nevertheless, there is evidence that fluoride has a multitude of direct and indirect effects on bacterial cells [51]. For instance, fluoride is known to exert antimicrobial modes of action against $S$. mutans, preventing its enrichment by directly inhibiting critical metabolic processes and by indirectly reducing environmental acidification in biofilms [52]. However, biofilm cell aggregates obstruct fluid flow, and hence fluoride mobility through their complex layers and to the tooth surface itself, the ultimate target of fluoride activity [53, 54]. Besides an insufficient insight on how biofilms actively control fluoride passage through their complex layers, transport by diffusion of small molecules or ions such as fluoride is relatively fast, but diffusion time increases with biofilm thickness and with the complexity of its exopolymeric matrix $[53,54]$. Therefore, biofilms with lower thickness and consequently simpler matrices will allow a higher rate of fluoride penetration [55], involving an easier destruction and faster removal, as noticed by differences in the evolution of COF recorded on cp-Ti with different biofilm biomass (Fig. 4).

In addition, the presence of calcium fluoride (or like) salts is also noticeable in Fig. 7a, widely spread over the surface, inside and outside the wear track, as well as attached to microbial cells, as shown in higher 
magnification in Fig. 7b, corroborating the OCP behavior of cp-Ti immersed in fluoridated AS solutions (Fig. 6). Figure $7 \mathrm{~b}$ also evidences the great affinity between microbial cells and the precipitated salts. Furthermore, the capacity of biofilms to re-adhere on Ti surfaces after being previously detached is shown in Fig. 7a by the microbial cells disposition on and around the wear track after the sliding test. Still, although a layer of cells together with calcium fluoride salts in the sliding track can protect the $\mathrm{Ti}$ surface against direct contact with the rubbing alumina ball, wear particles may still be released facilitating the surface destruction and generating a further debris removal.

Further investigation is needed to understand the simultaneous action of biofilms and fluoride on the biotribocorrosion behavior of Ti. The COF transition noticed in the presence of fluoride should be deeper analyzed by carrying out biotribocorrosion tests at different intervals to analyze the sliding track morphology before and after the transition. Another limitation of this study is the lack of chemical characterization of the precipitated salts. A subsequent study will investigate and report the synergistic effect of biofilms and fluoride on the electrochemical behavior of Ti surfaces.

\section{Conclusions}

Biotribological tests were performed on cp-Ti surfaces covered or not with biofilms immersed in AS in the absence or presence of fluoride (30 and $227 \mathrm{ppm} \mathrm{F}^{-}$). Mixed biofilm formation is influenced by the substrate topography: higher levels of biofilm biomass are formed on rougher surfaces. The lubricating properties of biofilms were confirmed by the low and constant COF registered, along with the presence of cells on the sliding area after reciprocating sliding wear, which emphasizes their protective effect on Ti oxide film and subsurface.

Fluoride ions in saliva act as a lubricant on $\mathrm{Ti}$ under sliding due to the precipitation of calcium fluoride (or like) salts, as verified by the slightly lower and higher OCP values, along with SEM images. This lubricant ability of fluoride has not been demonstrated before for dental implants. On the other hand, fluoride ions also facilitate the disruption of biofilms and their detachment in the sliding track. Biofilms with lower biomass reveal a transitional COF behavior, and a constant OCP in the presence of $227 \mathrm{ppm} \mathrm{F}^{-}$due to the higher rate of diffusion of fluoride ions. Therefore, it can be expected that fluoride significantly affects the biotribocorrosion behavior of $\mathrm{Ti}$ in the oral cavity.

Further investigation is needed to better understand the fluoride effect in biofilms, along with the mechanism of calcium fluoride precipitation, and to highlight their influence on the biotribocorrosion behavior of Ti.
Acknowledgments The authors would like to acknowledge Portuguese Foundation for Science and Technology (FCT) for the funding provided through R\&D projects PTDC/CTM/67500/2006, PTDC/CTM/68160/2006, UID/BIO/04469/2013; the project NORTE07-0124-FEDER-000027 co-funded by Programa Operacional Regional do Norte (ON.2 - O Novo Norte), QREN, FEDER; and the project RECI/BBB-EBI/0179/2012 (FCOMP-01-0124-FEDER027462). Special thanks to Martine Pauwels (Dept. Oral Health Sciences, KULeuven, Leuven, Belgium) and Wassim Zein Eddin (Dept. Materials Engineering, KULeuven, Leuven, Belgium) for all the assistance and support provided.

Conflict of interest On behalf of all authors, the corresponding author states that there is no conflict of interest.

Ethical standards The manuscript does not contain clinical studies or patient data.

\section{References}

1. Dierens M, Vandeweghe S, Kisch J, Nilner K, De Bruyn H (2012) Long-term follow-up of turned single implants placed in periodontally healthy patients after 16-22 years: radiographic and peri-implant outcome. Clin Oral Implants Res 23:197-204

2. Pye AD, Lockhart DEA, Dawson MP, Murray CA, Smith AJ (2009) A review of dental implants and infection. J Hosp Infect 72:104-110

3. Quirynen M, De Soete M, Van Steenberghe D (2002) Infections risk for oral implants: a review of literature. Clin Oral Implants Res 13:1-19

4. Roos-Jansåcker AM, Lindahl C, Renvert H, Renvert S (2006) Nine- to fourteen-year follow-up of implant treatment. Part III: factors associated with peri-implant lesions. J Clin Periodontol 33(4):296-301

5. Zhou ZR, Jin ZM (2015) Biotribology: recent progresses and future perspectives. Biosurface Biotribol 1(1):3-24. doi:10.1016/ j.bsbt.2015.03.001

6. Bruschi M, Steinmuller-Nethl D, Goriwoda W, Rasse M (2015) Composition and Modifications of Dental Implant Surfaces. J Oral Implants 2015:14. doi:10.1155/2015/527426

7. Branemark P-I (1983) Osseointegration and its experimental background. J Prosthet Dent 50(3):399-410. doi:10.1016/S00223913(83)80101-2

8. Palmquist A, Engqvist H, Lausmaa J, Thomsen P (2012) Commercially available dental implants: review of their surface characteristics. J Biomater Tissue Eng 2(2):112-124

9. Rocha LA, Oliveira F, Cruz HV, Sukotjo C, Mathew MT (2013) Bio-tribocorrosion in dental applications. In: Yan Y (ed) BioTribocorrosion in Biomaterials and Medical Implants. Woodhead Publishing Limited, Cambridge, pp 223-249

10. Landolt D, Mischler S, Stemp M, Barril S (2004) Third body effects and material fluxes in tribocorrosion systems involving a sliding contact. Wear 256(5):517-524

11. Antunes RA, de Oliveira MC (2012) Corrosion fatigue of biomedical metallic alloys: mechanisms and mitigation. Acta Biomater 8(3):937-962

12. Han MJ, Choe HC, Chung CH (2005) Surface Characteristics of Clinically Used Dental Implant Screws. Met Mater Int 11(6):449-456

13. Lilley PA, Walker PS, Blunn GW Wear of titanium by soft tissue. In: Transactions of the 4th World Biomaterials Congress, Berlin, 1992. pp 227-230

14. Diomidis N, Mischler S, More NS, Roy M (2012) Tribo-electrochemical characterization of metallic biomaterials for total joint replacement. Acta Biomater 8(2):852-859 
15. Souza JCM, Henriques M, Oliveira R, Teughels W, Celis J-P, Rocha LA (2010) Biofilms inducing ultra-low friction on titanium. J Dent Res 89(12):1470-1475

16. Cruz HV, Souza JCM, Henriques M, Rocha LA (2011) Tribocorrosion and bio-tribocorrosion in the oral environment: the case of dental implants. In: Davim JP (ed) Biomedical tribology. Nova Science Publishers Inc., New York, pp 1-30

17. Busscher HJ, Rinastiti M, Siswomihardjo W, van der Mei HC (2010) Biofilm formation on dental restorative and implant materials. J Dent Res 89(7):657-665

18. Covani U, Marconcini S, Crespi R, Barone A (2006) Bacterial plaque colonization around dental implant surfaces. Implant Dent 15:298-304

19. Saidin S, Kadir MRA, Sulaiman E, Kasim NHA (2012) Effects of different implant-abutment connections on micromotion and stress distribution: prediction of microgap formation. J Dent 40:467-474

20. Kumar PS, Mason MR, Brooker MR, O’Brien K (2012) Pyrosequencing reveals unique microbial signatures associated with healthy and failing dental implants. J Clin Periodontol 5(39):425-433

21. Burgers R, Hahnel S, Reichert TE, Rosentritt M, Behr M, Gerlach T, Handel G, Gosau M (2010) Adhesion of Candida albicans to various dental implant surfaces and the influence of salivary pellicle proteins. Acta Biomater 6(6):2307-2313

22. Souza JCM, Barbosa SL, Ariza E, Celis JP, Rocha LA (2012) Simultaneous degradation by corrosion and wear of titanium in artificial saliva containing fluorides. Wear 292-293:82-88

23. Horasawa N, Marek M (2010) Effect of fluoride from glass ionomer on discoloration and corrosion of titanium. Acta Biomater 6(2):662-666

24. Mabilleau G, Bourdon S, Joly-Guillou ML, Filmon R, Basle MF, Chappard D (2006) Influence of fluoride, hydrogen peroxide and lactic acid on the corrosion resistance of commercially pure titanium. Acta Biomater 2(1):121-129

25. Sivakumar B, Kumar S, Sankara Narayanan TSN (2011) Fretting corrosion behaviour of Ti-6Al-4 $\mathrm{V}$ alloy in artificial saliva containing varying concentrations of fluoride ions. Wear 270(3-4):317-324

26. Subramani K, Jung RE, Molenberg A, Hammerle CH (2009) Biofilm on dental implants-a review of the literature. Int J Oral Maxillofac Implants 24:616-626

27. Burgers R, Gerlach T, Hahnel S, Schwarz F, Handel G, Gosau M (2010) In vivo and in vitro biofilm formation on two different titanium implant surfaces. Clin Oral Implants Res 21:156-164

28. Teughels W, Van Assche N, Sliepen I, Quirynen M (2006) Effect of material characteristics and/or surface topography on biofilm development. Clin Oral Implants Res 17:68-81

29. Almaguer-Flores A, Ximenez-Fyvie LA, Rodil SE (2010) Oral bacterial adhesion on amorphous carbon and titanium films: effect of surface roughness and culture media. J Biomed Mater Res Part B 92:196-204

30. Barbour ME, O'Sullivan DJ, Jenkinson HF, Jagger DC (2007) The effects of polishing methods on surface morphology, roughness and bacterial colonisation of titanium abutments. J Mater Sci Mater Med 18(1):1439-1447

31. Frojd V, de Paz LC, Andersson M, Wennerberg A, Davies JR, Svensater G (2011) In situ analysis of multispecies biofilm formation on customized titanium surfaces. Mol Oral Microbiol 26:241-252

32. Harris LG, Meredith DO, Eschbach L, Richards RG (2007) Staphylococcus aureus adhesion to standard micro-rough and electropolished implant materials. J Mater Sci Mater Med 18:1151-1156
33. Okawa S, Watanabe K (2009) Chemical mechanical polishing of titanium with colloidal silica containing hydrogen peroxidemirror polishing and surface properties. Dent Mater J 28(1):68-74

34. Fusayama T, Katayori T, Nomoto S (1963) Corrosion of gold and amalgam placed in contact with each other. J Dent Res 42:1183-1197

35. Souza JCM, Henriques M, Oliveira R, Teughels W, Celis JP, Rocha LA (2010) Do oral biofilms influence the wear and corrosion behavior of titanium? Biofouling 26(4):471-478

36. Pereira-Cenci T, Deng DM, Kraneveld EA, Manders EMM, Cury AADB, ten Cate JM, Crielaard W (2008) The effect of Streptococcus mutans and Candida glabrata on Candida albicans biofilms formed on different surfaces. Arch Oral Biol 53(8):755-764

37. Watson PS, Pontefract HA, Devine DA, Shore RC, Nattress BR, Kirkham J, Robinson C (2005) Penetration of fluoride into natural plaque biofilms. J Dent Res 84(5):451-455

38. Gu G, Wu Z, Zhang Z, Qing F (2009) Tribological properties of fluorine-containing additives of silicone oil. Tribol Int 42:397402

39. Bartlett DW, Smith BG, Wilson RF (1994) Comparison of the effect of fluoride and non-fluoride toothpaste on tooth wear in vitro and the influence of enamel fluoride concentration and hardness of enamel. Br Dent J 176:346-348

40. Austin RS, Rodriguez JM, Dunne S, Moazzez R, Bartlett DW (2010) The effect of increasing sodium fluoride concentrations on erosion and attrition of enamel and dentine in vitro. J Dent 38:782-787

41. Lagerweij MD, Buchalla W, Kohnke S, Becker K, Lennon AM, Attin T (2006) Prevention of erosion and abrasion by a high fluoride concentration gel applied at high frequencies. Caries Res 40:148-153

42. Attin T, Zirkel C, Hellwig E (1998) Brushing abrasion of eroded dentin after application of sodium fluoride solutions. Caries Res 32:344-350

43. Magalhães AC, Rios D, Delbem AC, Buzalaf MA, Machado MA (2007) Influence of fluoride dentifrice on brushing abrasion of eroded human enamel: an in situ/ex vivo study. Caries Res 41:77-79

44. Ren YF, Liu X, Fadel N, Malmstrom H, Barnes V, Xu T (2011) Preventive effects of dentifrice containing $5000 \mathrm{ppm}$ fluoride against dental erosion in situ. J Dent 39(10):672-678

45. Magalhães AC, Wiegand A, Rios D, Honório HM, Buzalaf MA (2009) Insights into preventive measures for dental erosion. J Appl Oral Sci 17:75-86

46. ten Cate JM (1997) Review on fluoride, with special emphasis on calcium fluoride mechanisms in caries prevention. Eur J Oral Sci 105:461-465

47. Yang L, Wang S, Bozhu Hou L (2011) Sintering kinetics of selflubricating Ti-48\%Al-2\% Nb-2\%Cr alloys with fluoride lubricants. Adv Mater Res 295-297:432-435

48. Krishna PV, Srikant RR, Rao DN (2011) Solid lubricants in machining. Proc Inst Mech Eng Part J 225(4):213-227

49. Larsen MJ, Jensen SJ (1994) Experiments on the initiation of calcium fluoride formation with reference to the solubility of dental enamel and brushite. Arch Oral Biol 39:23-27

50. Wang JJ, Sanderson BJS, Wang H (2007) Cyto- and genotoxicity of ultrafine $\mathrm{TiO}_{2}$ particles in cultured human lymphoblastoid cells. Mutat Res 628:99-106

51. Hamilton IR, Bowden GHW (1988) Effect of fluoride on oral microorganisms. In: Ekstrand J, Fejerskov O, Silverstone LM (eds) Fluoride in dentistry, vol 1. Munksgaard, Copenhagen, pp 77-103 
52. Bradshaw DJ, Marsh PD, Hodgson RJ, Visser JM (2002) Effects of glucose and fluoride on competition and metabolism within in vitro dental bacterial communities and biofilms. Caries Res 36(2):81-86

53. Stoodley P, Wefel J, Gieseke A, deBeer D, von Ohle C (2008) Biofilm plaque and hydrodynamic effects on mass transfer, fluoride delivery and caries. J Am Dent Assoc 139:1182-1190
54. Aspiras M, Stoodley P, Nistico L, Longwell M, de Jager M (2010) Clinical implications of power toothbrushing on fluoride delivery: effects on biofilm plaque metabolism and physiology. Int J Dent. doi:10.1155/2010/651869

55. Stewart PS (2003) Diffusion in biofilms. J Bacteriol 185:14851491 